\title{
Temperament Affects Sympathetic Nervous Function in a Normal Population
}

\author{
Bora Kim, Jae-Hon Lee, Eun-Ho Kang and Bum-Hee Yu凶 \\ Department of Psychiatry, Samsung Medical Center, Sungkyunkwan University School of Medicine, Seoul, Republic of Korea
}

Objective Although specific temperaments have been known to be related to autonomic nervous function in some psychiatric disorders, there are few studies that have examined the relationship between temperaments and autonomic nervous function in a normal population. In this study, we examined the effect of temperament on the sympathetic nervous function in a normal population.

Methods Sixty eight healthy subjects participated in the present study. Temperament was assessed using the Korean version of the Cloninger Temperament and Character Inventory (TCI). Autonomic nervous function was determined by measuring skin temperature in a resting state, which was recorded for 5 minutes from the palmar surface of the left 5 th digit using a thermistor secured with a Velcro ${ }^{\circledR}$ band. Pearson's correlation analysis and multiple linear regression were used to examine the relationship between temperament and skin temperature.

Results A higher harm avoidance score was correlated with a lower skin temperature (i.e. an increased sympathetic tone; $r=-0.343$, $\mathrm{p}=0.004)$ whereas a higher persistence score was correlated with a higher skin temperature $(\mathrm{r}=0.433, \mathrm{p}=0.001)$. Hierarchical linear regression analysis revealed that harm avoidance was able to predict the variance of skin temperature independently, with a variance of $7.1 \%$ after controlling for sex, blood pressure and state anxiety and persistence was the factor predicting the variance of skin temperature with a variance of $5.0 \%$.

Conclusion These results suggest that high harm avoidance is related to an increased sympathetic nervous function whereas high persistence is related to decreased sympathetic nervous function in a normal population.

Psychiatry Investig 2012;9:293-297

Key Words Sympathetic nervous function, Temperament, Harm avoidance, Skin temperature.

\section{INTRODUCTION}

Biopsychosocial models provide an explanation for the understanding of personality, especially temperament, in terms of individual variance on the basis of genetics and neurobiology. ${ }^{1}$ According to Cloninger's model, the four dimensions of temperament are described as pertaining to novelty seeking (NS), harm avoidance (HA), reward dependence (RD), and persistence (P). NS defines the tendency to respond actively to novel stimuli and describes a genetic disposition towards being excitable, impulsive, exploratory, and quick-tempered. HA corresponds to the tendency toward an inhibitory response

Received: November 28, 2011 Revised: March 14, 2012

Accepted: April 9, 2012 Available online: September 6, 2012

$\triangle$ Correspondence: Bum-Hee Yu, MD, PhD

Department of Psychiatry, Samsung Medical Center, Sungkyunkwan University School of Medicine, 50 Irwon-dong, Gangnam-gu, Seoul 135-710, Republic of Korea

Tel: +82-2-3410-3583, Fax: +82-2-3410-0050, E-mail: bhyu@skku.edu

(a) This is an Open Access article distributed under the terms of the Creative Commons Attribution Non-Commercial License (http://creativecommons.org/licenses/by$\mathrm{nc} / 3.0$ ) which permits unrestricted non-commercial use, distribution, and reproduction in any medium, provided the original work is properly cited. to aversive stimuli and cautious, overly pessimistic behavior and thought. RD implies a tendency towards maintaining or continuing behavior, and is manifested as sensitivity, sentimentality, and dependence on other people's approval. $\mathrm{P}$ has relevance to continuing and persevering despite fatigue and lack of reward. ${ }^{2,3}$

Personality has been known to be closely related to the development of several physical illnesses, such as cardiovascular diseases (CVDs) and their risk factors. ${ }^{4,5}$ Moreover, Specific temperament is associated with autonomic cardiac regulation, ${ }^{6}$ and preclinical atherosclerosis which is risk factor of CVDs. ${ }^{7}$ However, only indirect effects of temperament on CVDs have been proposed to explain the linking mechanism between them. An acknowledged factor explaining the relationship between dimensions of temperament and the increased risk of CVDs is behavioral, i.e. the fact that individuals will have different lifestyles or coping strategies according to temperaments. ${ }^{5,7}$ In addition, some studies have shown that anger and hostility are strongly associated with coronary heart diseases (CHD), ${ }^{8}$ and especially anger suppression leads to 
cardiovascular risk and reactivity. ${ }^{9,10}$ As HA corresponds to the tendency toward an inhibitory response to aversive stimuli and cautious, overly pessimistic behavior, ${ }^{2}$ this inhibitory tendency may be related to anger suppression in a way, which may affect CHD outcome.

There is another possibility, that individuals scoring high or low on certain temperament dimensions are also prone to develop mental illnesses including depression and anxiety disorders, which increase sympathetic activities resulting in high cardiac morbidities and mortalities. ${ }^{11-15}$ Although depression and anxiety disorders as well as CVDs seem to be affected by high sympathetic activities, there is little data examining the direct impact of temperament on the sympathetic nervous function. Measuring skin temperature is a useful way to determine sympathetic activity because skin temperature is predominantly controlled by sympathetic nervous function, unlike blood pressure or heart rate which is controlled by both sympathetic and parasympathetic nervous functions. Thus, we aimed to examine the effect of temperament on sympathetic nervous function by examining skin temperature in a normal population.

\section{METHODS}

\section{Subjects}

The study was conducted in 68 normal subjects who were recruited by a local advertisement. The study group was composed of 35 women and 33 men, with a mean age ( \pm standard deviation) of 34.85 years $( \pm 8.92)$. The Institutional Review Board of the Samsung Medical Center approved the study, and informed consent was obtained from all participants. All participants underwent psychiatric interviewing using a structured psychiatric interview method (Mini-International Neuropsychiatric Interview Plus, MINI-plus) to exclude major psychiatric illnesses. They also underwent thorough medical interviewing to exclude major medical illnesses. These processes were conducted by two experienced psychiatrists, and all participants did not have any psychiatric illness according to the DSM-IV diagnostic criteria, and were also free of any major medical illnesses.

\section{Measures}

Temperament was assessed using the Korean version of the Cloninger Temperament and Character Inventory (TCI). ${ }^{16}$ The Spielberger's State Anxiety Inventory (STAI-S) was administered to all subjects. Skin temperature was used to determine sympathetic nervous function and was measured using a previously established method. ${ }^{17}$ Skin temperature reflects cutaneous circulation, which is controlled by the sympathetic vasoconstrictor and vasodilator nerves. Sympathetic activation stimulates postsynaptic $\alpha 1$ - and $\alpha 2$-receptors on cutaneous vessels and causes decreases in skin blood flow, which in turn, lowers skin temperature. ${ }^{18}$ Thus, low skin temperature reflects an increased sympathetic tone.

\section{Statistical analysis}

Correlation analyses among the four dimensions of temperament, age, sex, systolic blood pressure (SBP), diastolic blood pressure (DBP), STAI-S, and skin temperature were performed using Pearson's correlation analysis. Hierarchical multiple linear regression was performed to examine the predicting effect of temperament on skin temperature controlling for age, sex, SBP, DBP and STAI-S. Statistical significance was set at $\mathrm{p}<0.05$. All statistical analyses were performed using SPSS for Windows, ver. 17.0 (SPSS Inc, Chicago, IL, USA).

\section{RESULTS}

Table 1 presents the demographic and psychological characteristics of the study subjects. Table 2 shows correlations between skin temperature and dimensions of temperament. A higher harm avoidance (HA) score was related to a decreased skin temperature (i.e. an increased sympathetic tone; $r=$ $-0.343, \mathrm{p}=0.004)$. On the contrary, Persistence $(\mathrm{P})$ showed a positive correlation with skin temperature $(r=0.433, p=0.001)$. Other dimensions of temperament showed no significant correlations with skin temperature. A higher HA score was related to higher scores in STAI-S ( $\mathrm{r}=0.671, \mathrm{p}=0.001)$ and STAI$S$ was negatively correlated with skin temperature $(r=-0.255$, $\mathrm{p}=0.036)$ as expected. Age showed no significant ( $\mathrm{p}>0.1)$ correlation with skin temperature whereas female sex, high SBP

Table 1. Demographic and clinical characteristics of subjects $(\mathrm{N}=68)$

\begin{tabular}{lc}
\hline \multicolumn{1}{c}{ Variables } & Mean (SD or percentage) \\
\hline Age (years), mean (SD) & $34.85(8.92)$ \\
Sex & $35(51.5)$ \\
$\quad$ Females, N (\%) & $23.49(5.06)$ \\
BMI $\left(\mathrm{kg} / \mathrm{m}^{2}\right)$, mean (SD) & $65.36(8.54)$ \\
HR (bpm), mean (SD) & $38.91(10.08)$ \\
STAI-S, mean (SD) & $33.51(1.44)$ \\
Skin temperature $\left({ }^{\circ} \mathrm{C}\right)$, mean $(\mathrm{SD})$ & \\
Temperament & $30.66(11.74)$ \\
NS, mean (SD) & $30.65(11.74)$ \\
HA, mean (SD) & $45.56(8.81)$ \\
RD, mean (SD) & $48.03(11.78)$ \\
P, mean (SD)
\end{tabular}

Data are given as mean \pm standard deviation. BMI: body mass index, HR: heart rate, STAI-S: The Spielberger's State Anxiety Inventory, NS: novelty seeking, HA: harm avoidance, RD: reward dependence, $\mathrm{P}$ : persistence 
Table 2. Correlation coefficients among temperament and other variables including peripheral skin temperature $(\mathrm{N}=68)$

\begin{tabular}{llllllllllc}
\hline & Age & Sex & SBP & DBP & STAI-S & NS & HA & RD & P & ST \\
\hline Age & 1 & 0.143 & $0.425^{*}$ & $0.371^{*}$ & -0.060 & -0.043 & 0.024 & -0.200 & -0.033 & -0.111 \\
Sex & 0.143 & 1 & $-0.489^{*}$ & $-0.397^{*}$ & 0.091 & 0.022 & 0.008 & 0.234 & $-0.199^{*}$ & $-0.335^{*}$ \\
SBP & $0.425^{*}$ & $-0.489^{*}$ & 1 & $0.802^{*}$ & -0.129 & 0.078 & -0.064 & -0.092 & 0.222 & $0.246^{*}$ \\
DBP & $0.371^{*}$ & $-0.397^{*}$ & $0.802^{*}$ & 1 & -0.036 & 0.109 & 0.008 & 0.062 & $0.253^{*}$ & $0.424^{*}$ \\
STAI-S & -0.060 & 0.091 & -0.129 & -0.036 & 1 & 0.047 & $0.671^{*}$ & -0.181 & $-0.437^{*}$ & $-0.255^{*}$ \\
NS & -0.043 & 0.022 & 0.078 & 0.109 & 0.047 & 1 & 0.081 & 0.137 & $0.377^{*}$ & 0.099 \\
HA & 0.024 & 0.008 & -0.064 & 0.008 & $0.671^{*}$ & 0.081 & 1 & $-0.357^{*}$ & $-0.542^{*}$ & $-0.343^{*}$ \\
RD & -0.200 & 0.234 & -0.092 & 0.062 & -0.181 & 0.137 & $-0.357^{*}$ & 1 & $0.269^{*}$ & 0.203 \\
P & -0.033 & -0.199 & 0.222 & $0.253^{*}$ & $-0.437^{*}$ & $0.377^{*}$ & $-0.542^{*}$ & $0.269^{*}$ & 1 & $0.433^{*}$ \\
ST & -0.111 & $-0.335^{*}$ & $0.246^{*}$ & $0.424^{*}$ & $-0.255^{*}$ & 0.099 & $-0.343^{*}$ & 0.203 & $0.433^{*}$ & 1 \\
\hline
\end{tabular}

Regarding sex, 0 reflects men and 1 reflects women. NS: novelty seeking, HA: harm avoidance, RD: reward dependence, P: persistence, SBP: systolic blood pressure, DBP: diastolic blood pressure, STAI-S: The Spielberger's State Anxiety Inventory, ST: peripheral skin temperature

Table 3. Results of multiple linear regression analysis

\begin{tabular}{|c|c|c|c|c|c|c|c|}
\hline Skin temperature & $\beta$ & $\mathrm{p}$ & $\mathrm{t}$ & $\mathrm{R}^{2}$ & $\Delta \mathrm{R}^{2}$ & $\mathrm{~F}$ & $\mathrm{P}$ \\
\hline Step1 & & & & 0.332 & & 7.822 & 0.001 \\
\hline Sex & -0.764 & 0.027 & -2.266 & & & & \\
\hline SBP & -0.051 & 0.014 & -2.534 & & & & \\
\hline DBP & 0.101 & 0.001 & 3.926 & & & & \\
\hline STAI-S & -0.038 & 0.013 & -2.548 & & & & \\
\hline Step2-A & & & & 0.403 & 0.071 & 8.359 & 0.001 \\
\hline Sex & -0.820 & 0.013 & -2.547 & & & & \\
\hline SBP & -0.052 & 0.008 & -2.728 & & & & \\
\hline $\mathrm{DBP}$ & 0.103 & 0.001 & 4.199 & & & & \\
\hline STAI-S & -0.003 & 0.857 & -0.180 & & & & \\
\hline HA & -0.044 & 0.009 & -2.711 & & & & \\
\hline Step2-B & & & & 0.382 & 0.050 & 7.677 & 0.001 \\
\hline Sex & -0.688 & 0.040 & -2.097 & & & & \\
\hline SBP & -0.047 & 0.018 & -2.436 & & & & \\
\hline DBP & 0.090 & 0.001 & 3.529 & & & & \\
\hline STAI-S & -0.022 & 0.178 & -1.361 & & & & \\
\hline $\mathrm{P}$ & -0.41 & 0.028 & 2.252 & & & & \\
\hline
\end{tabular}

$\beta$ : standardized coefficients, HA: harm avoidance, P: persistence, SBP: systolic blood pressure, DBP: diastolic blood pressure, STAI-S: The Spielberger's State Anxiety Inventory

and DBP were significantly associated with decreased skin temperatures $(\mathrm{r}=-0.437, \mathrm{p}=0.005 ; \mathrm{r}=0.246, \mathrm{p}=0.043 ; \mathrm{r}=0.424$, $\mathrm{p}=0.001$, respectively) (Table 2 ).

By multivariate analysis using hierarchical multiple linear regression, HA was found to be the predicting variable among temperaments to account for a low skin temperature after controlling for sex, DBP, SBP, and STAI-S ( $\mathrm{p}=0.001, \Delta \mathrm{R}^{2}=0.071$ ) (Table 3 ). In addition, $\mathrm{P}$ was the predicting variable to account for high skin temperature after controlling for sex, DBP, SBP, and STAI-S ( $\left.\mathrm{p}=0.001, \Delta \mathrm{R}^{2}=0.050\right)$ (Table 3$)$.

\section{DISCUSSION}

The present study showed that individuals with high HA have decreased skin temperature (i.e. increased sympathetic nervous function) whereas individuals with high $\mathrm{P}$ have increased skin temperature. These results suggest that high HA predicts increased sympathetic nervous function whereas high $\mathrm{P}$ predicts decreased sympathetic nervous function. Many pathologic conditions, including CVDs as well as several psychiatric disorders, have been suggested to be related to both neurotic or anxious personality traits and to increased sym- 
pathetic nervous function. ${ }^{12,16,19,20}$ As state anxiety showed a highly positive correlation with HA in this study, our findings provide evidence of a link between neurotic or anxious personalities and the development of CVDs which are associated with increased sympathetic nervous function.

We suggest two explanations for the underlying mechanism linking high HA to increased sympathetic nervous system. Firstly, HA reflects an inheritable disposition towards anxiety, caution, and pessimism, characteristics that make people feel anxious more easily. ${ }^{3}$ Our results showed that subjects with high anxiety levels have high HA and low skin temperatures. This is consistent with previous finding that anxiety is closely related to the functions of the autonomic nervous system. ${ }^{21}$ Thus, it is plausible that high HA leads to increased level of anxiety, which, in turn, results in increased sympathetic nervous function. Another possible explanation is that HA may affect sympathetic nervous function through the serotonergic system. In addition, HA is known to be associated with serotonin transporter polymorphism ${ }^{22}$ and the serotonergic system is known to play a key regulatory role in the sympathetic nervous system through controlling vascular conductance and hemodynamic changes. ${ }^{23,24}$ Thus, HA may directly affect sympathetic nervous function through an altered serotonergic system.

In addition, our findings suggest that $\mathrm{P}$ may have protective effect on CVDs since high $\mathrm{P}$ showed a negative correlation with sympathetic nervous function. High persistence is associated with industriousness, perseverance and perfectionism, and implies a heritable bias towards continuing and persevering despite fatigue and lack of reward. ${ }^{3}$ Thus, we can assume that $\mathrm{P}$ has protective effect on CVDs. As there is little direct evidence supporting the protective effect of $\mathrm{P}$ on CVDs, further studies will be needed to prove it.

In this study, we measured systolic blood pressure (SBP) and diastolic blood pressure (DBP) to figure out the effect of blood pressure on sympathetic nervous function. Previous studies to examine the relationship between blood pressure and CVDs showed that SBP is more strongly related to the risk of cardiovascular disease than $\mathrm{DBP}^{25,26}$ In our study, we tried to explore different influences of SBP and DBP on sympathetic nervous function, respectively, but we found that both SBP and DBP significantly affect peripheral skin temperature. As our study included only 68 normal healthy subjects, further study with a larger sample will be needed to examine the exact mechanism of blood pressure effect on sympathetic nervous function in a general population.

This study has some limitations. Firstly, the number of subjects was relatively too small to extend this finding to the general population. Secondly, as we measured only sympathetic nervous function using skin temperatures, we could not assess overall autonomic nervous function, which is determined by the balance between the sympathetic and parasympathetic functions. Thirdly, an age bias could affect the results of the study since our subjects were relatively too young.

In conclusion, a temperament of high harm avoidance is related to an elevated sympathetic nervous function and high persistence has relation with lower sympathetic nervous function in a normal population. Thus, temperament may be an important factor in some medical and psychiatric illnesses which are known to be associated with the sympathetic nervous function.

\section{Acknowledgments}

This study was supported by the Samsung Biomedical Research Institute (SBRI), with a grant number of C-A9-222. The SBRI was not involved in the creation of the study protocol, data analysis, data interpretation, or in writing the manuscript.

\section{REFERENCES}

1. Engel GL. The need for a new medical model: a challenge for biomedicine. Science 1977;196:129-136.

2. Cloninger CR. A systematic method for clinical description and classification of personality variants. A proposal. Arch Gen Psychiatry 1987; 44:573-588.

3. Cloninger CR, Svrakic DM, Przybeck TR. A psychobiological model of temperament and character. Arch Gen Psychiatry 1993;50:975-990.

4. Keltikangas-Jarvinen L, Ravaja N, Viikari J. Identifying Cloninger's temperament profiles as related to the early development of the metabolic cardiovascular syndrome in young men. Arterioscler Thromb Vasc Biol 1999;19:1998-2006.

5. Sovio U, King V, Miettunen J, Ek E, Laitinen J, Joukamaa M, et al. Cloninger's Temperament dimensions, socio-economic and lifestyle factors and metabolic syndrome markers at age 31 years in the Northern Finland Birth Cohort 1966. J Health Psychol 2007;12:371-382.

6. Puttonen S, Elovainio M, Kivimaki M, Koskinen T, Pulkki-Raback L, Viikari JS, et al. Temperament, health-related behaviors, and autonomic cardiac regulation: the cardiovascular risk in young Finns study. Biol Psychol 2008;78:204-210.

7. Hintsanen M, Pulkki-Raback L, Juonala M, Viikari JS, Raitakari OT, Keltikangas-Jarvinen L. Cloninger's temperament traits and preclinical atherosclerosis: the Cardiovascular Risk in Young Finns Study. J Psychosom Res 2009;67:77-84.

8. Bongard S, al'Absi M, Lovallo WR. Interactive effects of trait hostility and anger expression on cardiovascular reactivity in young men. Int J Psychophysiol 1998;28:181-191.

9. Vogele C, Jarvis A, Cheeseman K. Anger suppression, reactivity, and hypertension risk: gender makes a difference. Ann Behav Med 1997;19: 61-69.

10. Harburg E, Julius M, Kaciroti N, Gleiberman L, Schork MA. Expressive/ suppressive anger-coping responses, gender, and types of mortality: a 17-year follow-up (Tecumseh, Michigan, 1971-1988). Psychosom Med 2003;65:588-597.

11. Hirano S, Sato T, Narita T, Kusunoki K, Ozaki N, Kimura S, et al. Evaluating the state dependency of the Temperament and Character Inventory dimensions in patients with major depression: a methodological contribution. J Affect Disord 2002;69:31-38.

12. Strakowski SM, Dunayevich E, Keck PE Jr, McElroy SL. Affective state dependence of the Tridimensional Personality Questionnaire. Psychiatry Res 1995;57:209-214.

13. Aromaa A, Raitasalo R, Reunanen A, Impivaara O, Heliovaara M, Knekt $\mathrm{P}$, et al. Depression and cardiovascular diseases. Acta Psychiatr Scand Suppl 1994;377:77-82.

14. Pratt LA, Ford DE, Crum RM, Armenian HK, Gallo JJ, Eaton WW. De- 
pression, psychotropic medication, and risk of myocardial infarction. Prospective data from the Baltimore ECA follow-up. Circulation 1996; 94:3123-3129.

15. Frasure-Smith N, Lesperance F, Talajic M. Depression following myocardial infarction. Impact on 6-month survival. JAMA 1993;270:18191825.

16. Sung SM, Kim JH, Yang E, Abrams KY, Lyoo IK. Reliability and validity of the Korean version of the Temperament and Character Inventory. Compr Psychiatry 2002;43:235-243.

17. Kang EH, Song YJ, Kim KJ, Shim HB, Park JE, Yu BH. Sympathetic nervous function and the effect of the catechol-O-methyltransferase $\mathrm{Val}(158)$ Met polymorphism in patients with panic disorder. J Affect Disord 2010;123:337-340.

18. Charkoudian N. Skin blood flow in adult human thermoregulation: how it works, when it does not, and why. Mayo Clin Proc 2003;78:603612 .

19. Hansenne M, Reggers J, Pinto E, Kjiri K, Ajamier A, Ansseau M. Temperament and character inventory (TCI) and depression. J Psychiatr Res 1999;33:31-36

20. Smith DJ, Duffy L, Stewart ME, Muir WJ, Blackwood DH. High harm avoidance and low self-directedness in euthymic young adults with recurrent, early-onset depression. J Affect Disord 2005;87:83-89.

21. Cullen TD, Wenger MA. Studies of Autonomic Balance in Children and Adults. New York: Holt, Rinehart \& Winston; 1972.

22. Lesch KP, Bengel D, Heils A, Sabol SZ, Greenberg BD, Petri S, et al. Association of anxiety-related traits with a polymorphism in the serotonin transporter gene regulatory region. Science 1996;274:1527-1531.

23. Lovick TA. Cardiovascular responses to $5-\mathrm{HT}$ in the ventrolateral medulla of the rat. J Auton Nerv Syst 1989;28:35-41.

24. Lovick TA. Systemic and regional haemodynamic responses to microinjection of 5-HT agonists in the rostral ventrolateral medulla in the rat. Neurosci Lett 1989;107:157-161.

25. Haider AW, Larson MG, Franklin SS, Levy D; Framingham Heart Study. Systolic blood pressure, diastolic blood pressure, and pulse pressure as predictors of risk for congestive heart failure in the Framingham Heart Study. Ann Intern Med 2003;138:10-16.

26. Stamler J, Stamler R, Neaton JD. Blood pressure, systolic and diastolic, and cardiovascular risks. US population data. Arch Intern Med 1993; 153:598-615. 